Sung Hyun Kim

\title{
Ethik als Gütertheorie
}

Eine systematisch-historische Relektüre von G. E. Moores "Principia Ethica»

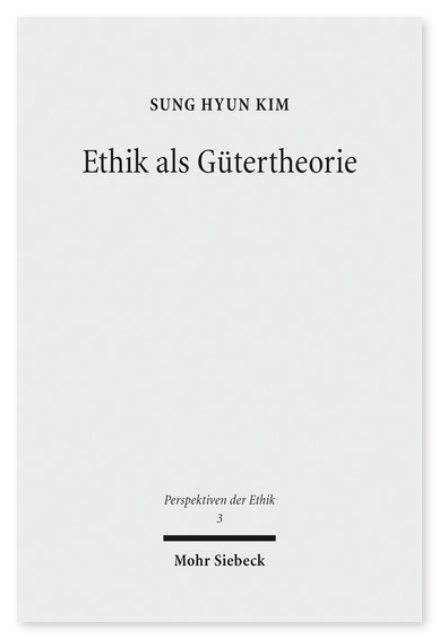

2015. XII, 239 Seiten. PE 3

ISBN 978-3-16-153750-9

DOI 10.1628/978-3-16-153750-9

eBook PDF 74,00€

ISBN 978-3-16-153679-3

fadengeheftete Broschur 74,00€
Alle Verwirrungen und Irrtümer der ethischen Theoriebildung können nach G. E. Moore beseitigt werden, wenn nur der Gegenstand der Ethik klar erfasst wird. Dieser aber steht jedem vor Augen, wenn er auf die Frage antworten muss: »Was ist 'gut'?« Mit der Besinnung auf das, was »in sich gut« ist, hat G. E. Moore mit seinem Werk Principia Ethica den Vorstoß zu einer Ethik als Gütertheorie unternommen. Sung Hyun Kim zeigt, dass, wenn dieser prolegomenarische Anspruch ernst genommen wird, die Frage nach Gewissheit die Grundfrage einer jeden Ethik darstellt.

Sung Hyun Kim Geboren 1976; Studium der Ev. Theologie in Berlin, Jerusalem und Tübingen; Vikariat in Betzingen-Reutlingen; Pfarrer zur Dienstaushilfe beim Dekan in Ludwigsburg; Repetent am Ev. Stift Tübingen; 2013 Promotion; seit 2014 Pfarrer in Mähringen/Immenhausen bei Tübingen.

Jetzt bestellen:

https://mohrsiebeck.com/buch/ethik-als-guetertheorie-9783161537509?no_cache=1

order@mohrsiebeck.com

Telefon: +49 (0)7071-923-17

Telefax: $+49(0) 7071-51104$ 